\title{
Cephalometric study to test the reliability of anteroposterior skeletal discrepancy indicators using the twin block appliance
}

\author{
Rahul Trivedi ${ }^{1}$, Amit Bhattacharya ${ }^{1}$, Falguni Mehta ${ }^{1}$, Dolly Patel ${ }^{2}$, Harshik Parekh ${ }^{1}$ and Vaibhav Gandhi ${ }^{* *}$
}

\begin{abstract}
Background: The objectives of this study were to check the reliability of the five angular and two linear parameters for sagittal maxillo-mandibular discrepancy and to compare and correlate angular parameters with the ANB angle, and the linear parameter with Wits analysis.

Methods: The pre-treatment and post-functional lateral cephalograms of 25 subjects ( 17 males, 8 females) with class II division 1 malocclusion treated with twin block functional appliance were selected. Five angular (ANB, $\beta$ angle, APDI, YEN angle, $W$ angle) and two linear (Wits analysis, App-Bpp) parameters were traced on both sets of cephalograms. Paired Student's $t$-test, one-way ANOVA, post hoc test, and Karl Pearson correlation statistical analysis were performed.
\end{abstract}

Results: All the parameters considered in our study showed highly significant difference in pre-treatment and post-functional values, suggesting their reliability $(p<0.0001)$. When ANB angle was compared with the other angular parameters, a highly significant change in the mean value of the difference in pre-treatment $(T 1)$ and post-functional (T2) values was noted $(p<0.001)$. No significant change was seen when comparing the mean value of the difference in T1 and T2 between linear parameters $(p=0.949)$.

Conclusions: All the parameters used in the study can be reliably used to assess anteroposterior skeletal discrepancy. Whenever limitations of the ANB angle and Wits analysis are foreseen, the W angle and App-Bpp, respectively, can be reliably used. The YEN angle may reliably predict the post-functional change with the use of twin block appliance.

Keywords: Anteroposterior discrepancy parameters; Twin block; Lateral cephalogram; Reliability

\section{Background}

Patients seeking orthodontic treatment frequently fall in the skeletal class II category. The National Health and Nutrition Examination Survey estimated, based on overjet, that approximately $14.7 \%$ of the US population has class II malocclusion, with prevalence decreasing from $22.6 \%$ between 8 and 11 years of age, to $15.6 \%$ between 12 and 17 years of age and then to $13.4 \%$ between 18 and 50 years of age [1]. The National Center for Health Statistics reported that $20.4 \%$ of 6 - to 11 -year-olds have bilateral class II molar relationships, compared with

\footnotetext{
* Correspondence: smiledesigner1988@gmail.com

'Department of Orthodontics, Government Dental College and Hospital, Asarva, Ahmedabad, 380016, Gujarat, India

Full list of author information is available at the end of the article
}

$14.5 \%$ of 12 - to 17 -year-olds [2,3]. The prevalence of skeletal class II type of malocclusion in the Indian population is $14.6 \%$ for the age group of 10 to 13 years, $6 \%$ for the age group of 5 to 9 years, and 3.8\% for the age group of 6 to 14 years [4]. Although maxillary protrusion and mandibular retrognathism are both found to be possible causative factors, McNamara reported mandibular retrognathism to be more common for skeletal class II malocclusion [5].

Evaluation of anteroposterior jaw discrepancy for diagnosis and treatment planning is one of the primary requirements in the field of orthodontics. Numerous authors have tried to assess the sagittal skeletal relationship using various landmarks, starting from Riedel (ANB angle) [6], Jacobson (Wits analysis) [7], Nanda

\section{实}


Table 1 Short description of various parameters used in the study

\begin{tabular}{|c|c|}
\hline Parameter & Short description \\
\hline ANB & $\begin{array}{l}\text { The angle formed by the intersection of the point } \\
\text { A to } N \text { (nasion) line and the point B to } N \text { (nasion) } \\
\text { line (Figure 1) }\end{array}$ \\
\hline$\beta$ angle & $\begin{array}{l}\text { A perpendicular is dropped from point } A \text { to a line } \\
\text { drawn from } C \text { (center of condyle) to point B. } \beta \text { angle } \\
\text { is the angle between this perpendicular and the A-B } \\
\text { line (Figure } 2 \text { ) }\end{array}$ \\
\hline YEN angle & $\begin{array}{l}\text { Angle between the } S \text { (sella) to } M \text { (center of the } \\
\text { premaxilla) line and the M to D (center of the } \\
\text { symphysis) line (Figure } 3 \text { ) }\end{array}$ \\
\hline W angle & $\begin{array}{l}\text { A perpendicular is dropped from } M \text { to the } S-D \text { line. } \\
W \text { angle is measured between this perpendicular } \\
\text { and the } M-D \text { line (Figure } 4 \text { ) }\end{array}$ \\
\hline APDI & $\begin{array}{l}(\mathrm{NPg}-\mathrm{FH} \text { plane }) \pm(\mathrm{NPg}-\mathrm{AB}) \pm(\mathrm{FH} \text {-palatal plane }) \\
\text { (Figure 5) }\end{array}$ \\
\hline Wits appraisal & $\begin{array}{l}\text { Distance between the projection of point } A \text { and } \\
\text { point } B \text { on the occlusal plane (Figure } 6 \text { ) }\end{array}$ \\
\hline App-Bpp & $\begin{array}{l}\text { Distance between the projection of point A and } \\
\text { point B on the palatal plane (Figure 6) }\end{array}$ \\
\hline
\end{tabular}

and Merrill (App-Bpp) [8], Baik and Ververidou ( $\beta$ angle) [9], Kim and Vietas (APDI) [10], Neela et al. (YEN angle) [11], Bhad (W angle) [12], etc. The ANB angle and Wits analysis are still one of the most commonly and reliably used parameters in assessing maxillo-mandibular relation, although there is not a single diagnostic test or cephalometric measurement that has been accepted to be used as the 'gold standard' for defining class II or class III skeletal patterns [13-16]. Accurate location of the cephalometric landmarks, growth changes, orthodontic treatment, etc. may influence the accurate assessment of the sagittal skeletal discrepancy. Limitations of these measurements add to the confusion regarding the reliability of these parameters to assess anteroposterior jaw discrepancy.

The treatment for class II malocclusion varies from skeletal growth modification to camouflage to orthognathic surgery depending upon the age of the patient. It is a well-known fact that the twin block appliance developed by Clark is an effective class II corrector in skeletal growth modification [17-19]. Although many studies have been carried out and documented showing anteroposterior skeletal assessment with twin block appliance,

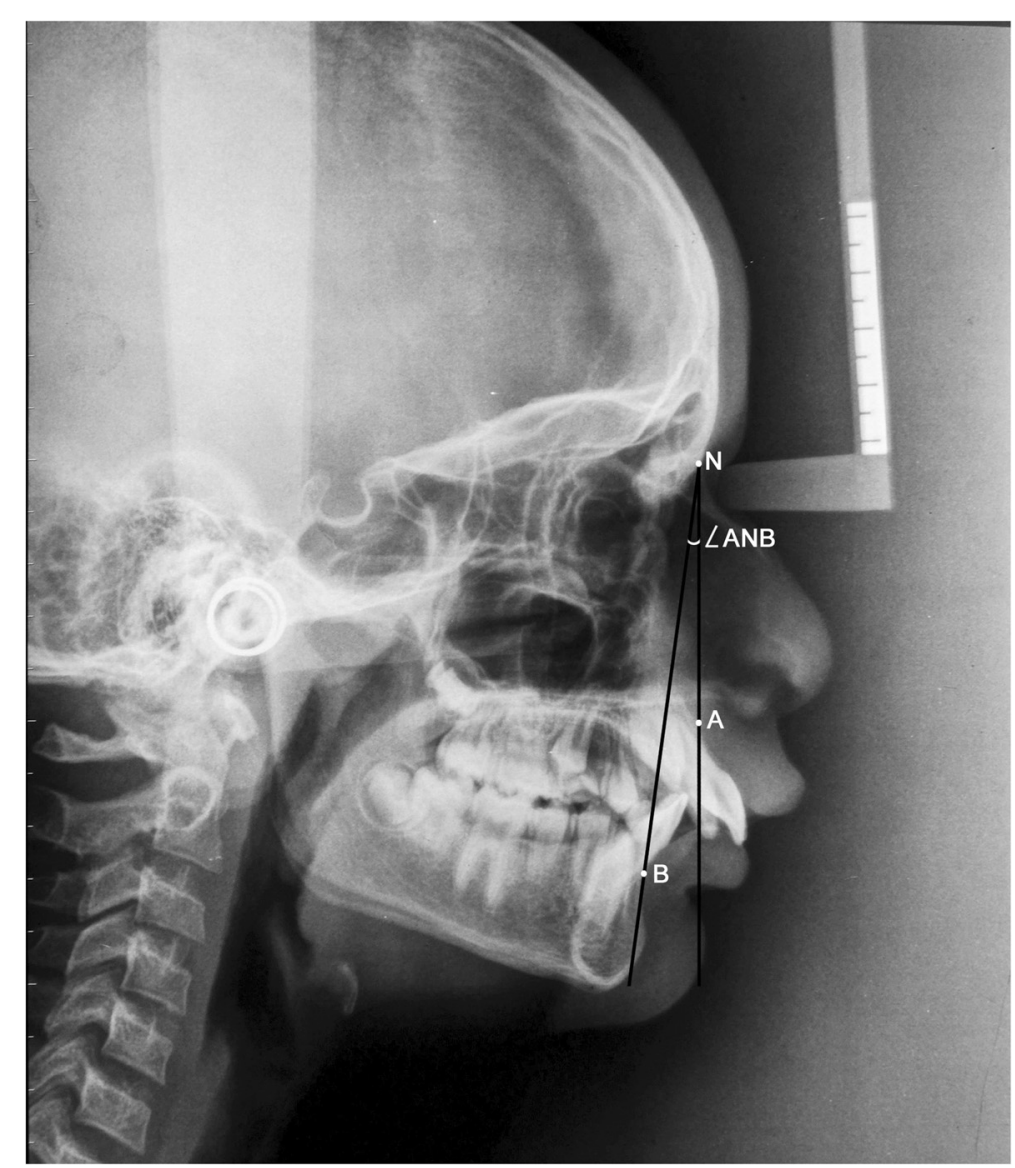

Figure 1 Angular parameter ANB. 
no study has been conducted comparing and correlating all the parameters of sagittal changes using twin block. So it was considered worthwhile to do quantitative appraisal of the reliability of five angular and two linear sagittal skeletal discrepancy parameters to assess the result of using twin block appliance for correction of class II malocclusion. Taking the above stated fact into consideration, it was decided to assess the change in the maxillo-mandibular relation using five angular (ANB angle, APDI, $\beta$ angle, W angle, YEN angle) and two linear (Wits analysis and App-Bpp) anteroposterior discrepancy parameters in patients who were treated with the twin block appliance.

The objectives of the study thus were as follows:

- To check the reliability of the angular and linear parameters considered in our study

- To compare and correlate the angular parameters

- To compare and correlate the linear parameters

- To evaluate which of the above parameters best predicts the sagittal correction after twin block therapy

\section{Methods}

The present cephalometric study was undertaken from the records available in the Department of Orthodontics Govt. Dental College and Hospital. Twenty-five cases (17 males, 8 females) in the age range of 11 to 14 years having CVMI in stages III and IV who fulfilled the following inclusion criteria were selected for the study:

1. Angle's class II division 1 malocclusion as evaluated from the dental study casts

2. ANB angle greater than $4^{\circ}$ with mandibular deficiency

3. Overjet ranging from 6 to $15 \mathrm{~mm}$ with a mean of $10 \mathrm{~mm}$

4. No prior orthodontic treatment

5. Subjects treated with only removable twin block functional appliance

All subjects were given modified twin block appliance with jack screw and labial bow incorporated in the maxillary plate. They were regularly called for follow-up and evaluated for sagittal correction. After bilateral molar class I reduction in overjet and after significant improvement in profile was achieved, post-functional records were made.

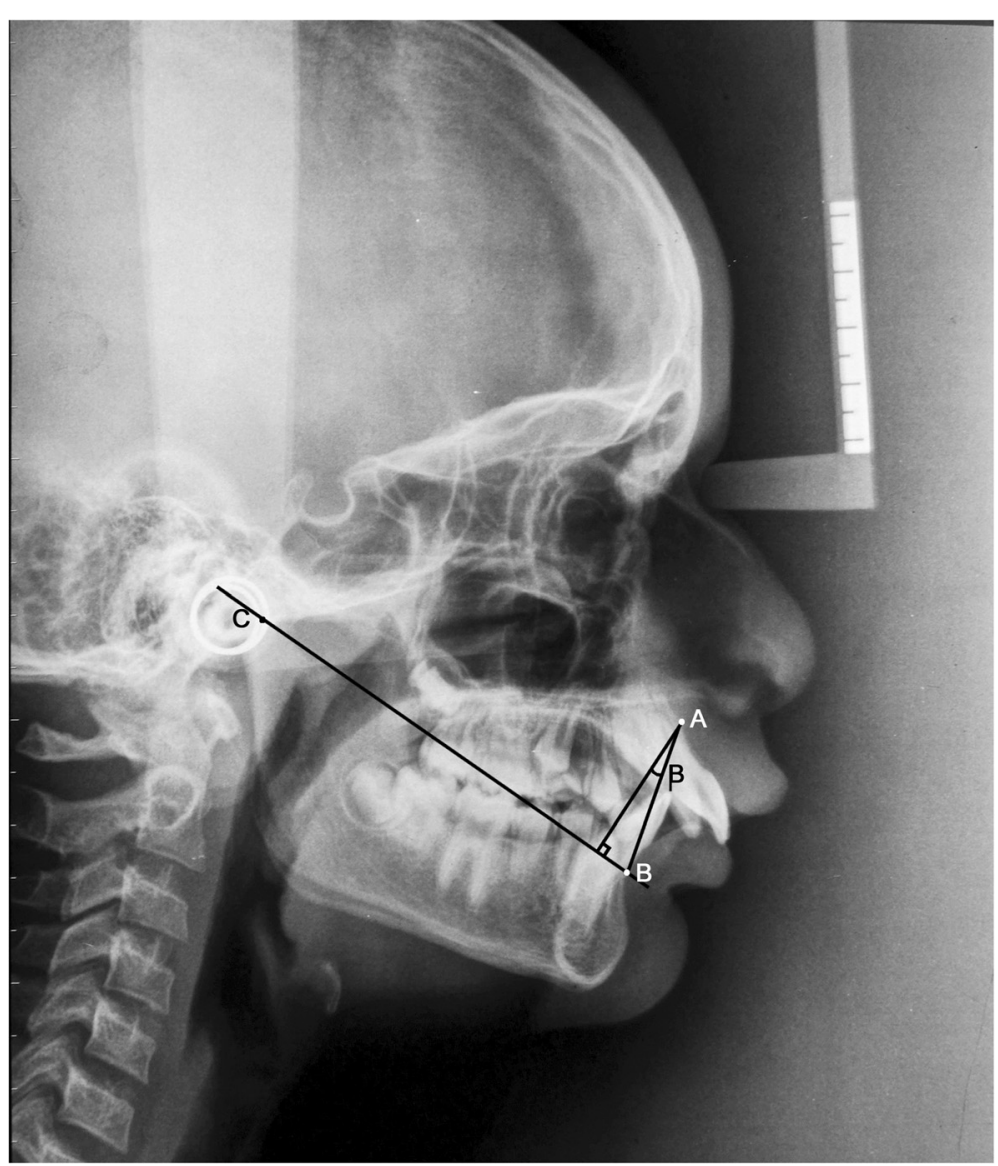

Figure 2 Angular parameter $\beta$ angle. 
The average treatment time of twin block functional appliance therapy was 11 months.

Pre-treatment (T1) and post-functional (T2) lateral cephalograms were obtained and traced by a single operator. Five angular and two linear parameters were taken for both sets of cephalograms and were compared and evaluated.

The angular parameters used were as follows (Table 1):

- ANB angle (Figure 1)

- $\beta$ angle (Figure 2)

- YEN angle (Figure 3)

- W angle (Figure 4)

- APDI (Figure 5)

The linear parameters used were as follows (Figure 6, Table 1):

- Wits analysis

- App-Bpp

The resultant data was subjected to statistical analysis. Paired sample $t$-test was performed to evaluate the differences in the pre-treatment (T1) and post-functional (T2) values (Table 2 ) in the angular and linear parameters. ANOVA (Table 3) and Tukey HSD post hoc test (Table 4) for multiple comparisons were done to evaluate change in the mean of the difference between $\mathrm{T} 1$ and $\mathrm{T} 2$ values of the parameters. Correlations between angular parameters and linear parameters were assessed using the Karl Pearson correlation coefficient test (Table 5). The ability of a parameter to predict the probable change in the sagittal plane after treatment with the twin block appliance was evaluated using regression equations as well as the standard error of the estimate (Table 6). $r$, the multiple correlation coefficient, is the linear correlation between the observed and model-predicted values of the dependent variable. $r^{2}$, the coefficient of determination, is the squared value of the multiple correlation coefficient. It shows that about half the variation in time is explained by the model.

Approval for this study was obtained from the institutional review board of the Govt. Dental College and Hospital, Ahmedabad, with informed consents from the parents or guardians of all subjects.

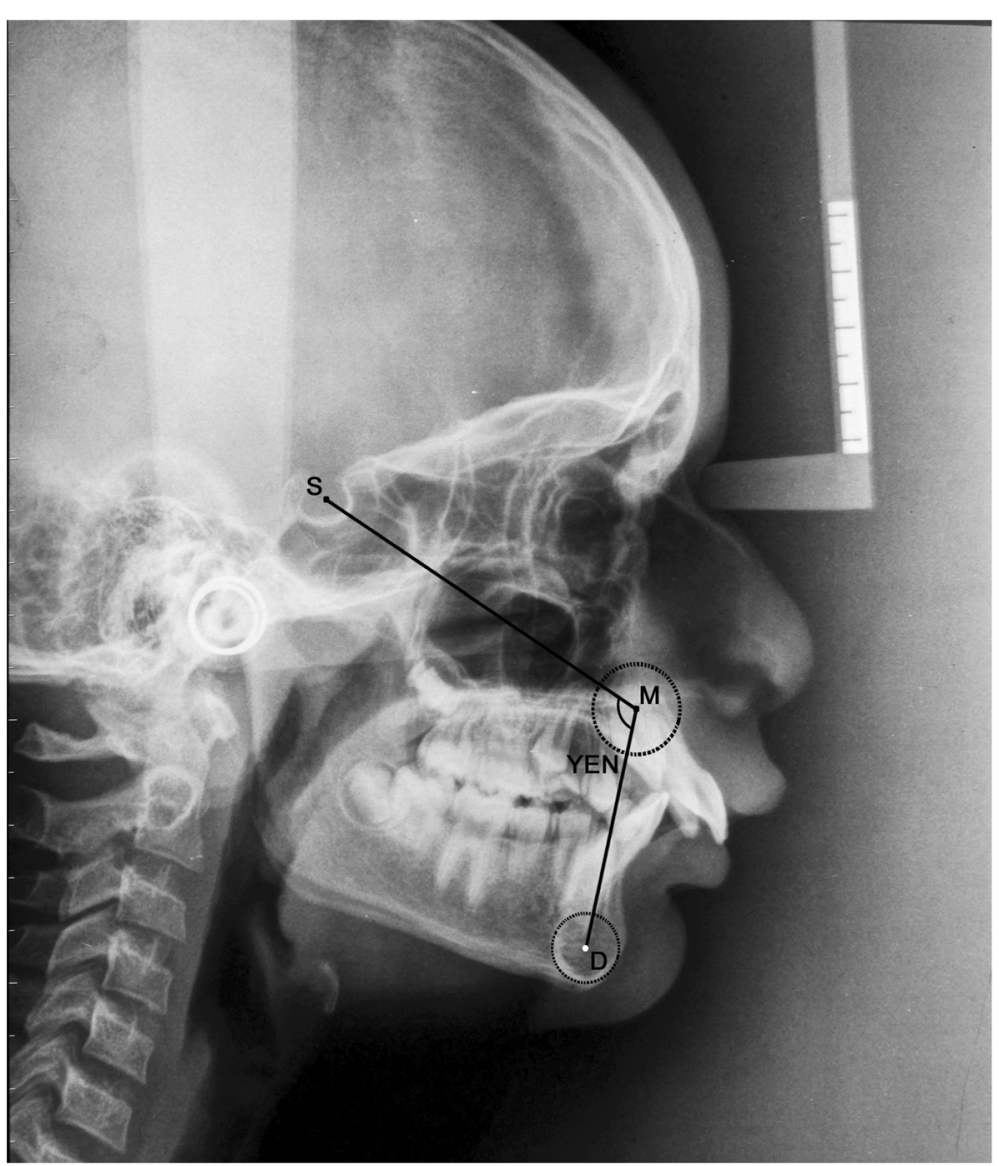

Figure 3 Angular parameter YEN angle. 


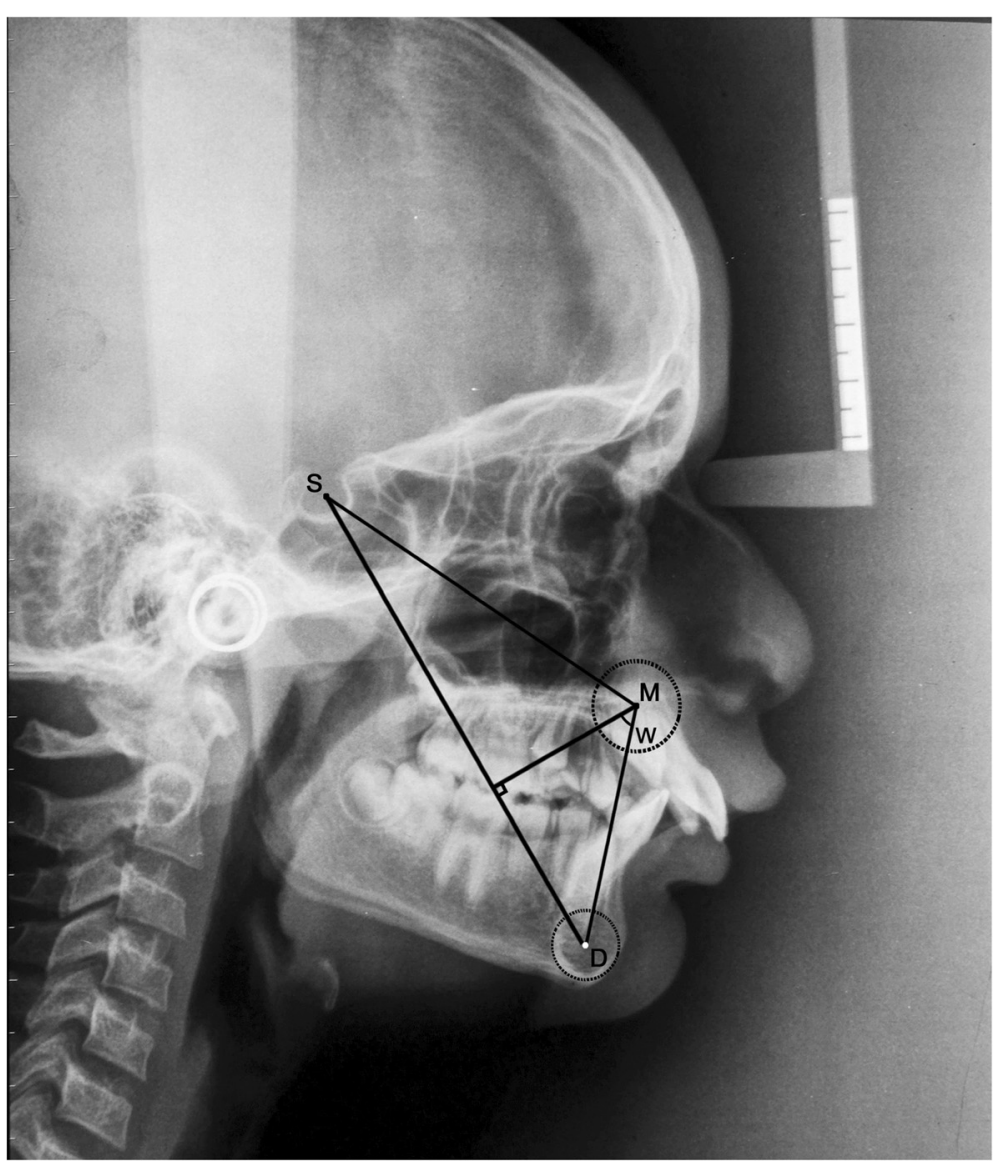

Figure 4 Angular parameter W angle.

\section{Results and discussion}

Paired sample $t$-test results showed highly significant changes between $\mathrm{T} 1$ and $\mathrm{T} 2$ for all the seven anteroposterior discrepancy parameters $(p<0.0001)$ (Table 2$)$.

The ANOVA test showed the variation in the mean of the difference between $\mathrm{T} 1$ and $\mathrm{T} 2$ of all seven parameters to be highly significant $(p<0.0001)$ (Table 3$)$.

Furthermore, when the ANB angle was compared with the other four angular parameters, a highly significant change in the mean of the difference between $\mathrm{T} 1$ and $\mathrm{T} 2$ values was noted (Table 4).

No significant change was seen when comparing the mean of the difference between $\mathrm{T} 1$ and $\mathrm{T} 2$ of the linear parameters $(p=0.949)$ (Table 5).

The change in the mean of the difference between T1 and T2 was highly significant for the $\beta$ angle and YEN angle, $\beta$ angle and $\mathrm{W}$ angle, and APDI and $\mathrm{W}$ angle $(p<$ $0.0001)$ and were non-significant for the $\beta$ angle and APDI $(p=0.927)$, and YEN angle and W angle $(p=0.982)$ (Table 4$)$.

The Karl Pearson correlation test showed moderately negative but significant correlations for the angular parameters when they were compared to the ANB angle (Table 4). The highest correlations of all angular parameters compared with the ANB were observed for the $\mathrm{W}$ angle $(r=-0.613)$. Moderately positive and significant correlation between App-Bpp and Wits analysis was also noted (Table 5). Strongly positive and highly significant correlations were observed only between the YEN angle and W angle $(r=0.894, p<0.0001)$ (Table 5).

Regression equation analysis calculated for the YEN angle $(Y=0.940 * X+11.697)$ had the highest correlation coefficient $\left(r=0.86, r^{2}=0.74\right)$. The standard error of the estimate was found to be least for ANB (0.95) (Table 6).

In our study, changes in the anteroposterior plane were assessed in the same group of patients after giving them a functional appliance, thus removing the subject error. The ultimate goals of this study were to assess the reliability of five angular and two linear sagittal skeletal discrepancy parameters and to compare and correlate the angular parameters ( $\beta$ angle, APDI, $W$ angle, and YEN angle) with the universally accepted ANB angle, and the linear parameter App-Bpp with Wits analysis, as indicators of successful twin block therapy in growing subjects.

The primary objective to use twin block appliance was because it is a proven potent class II corrector [17-19]. 


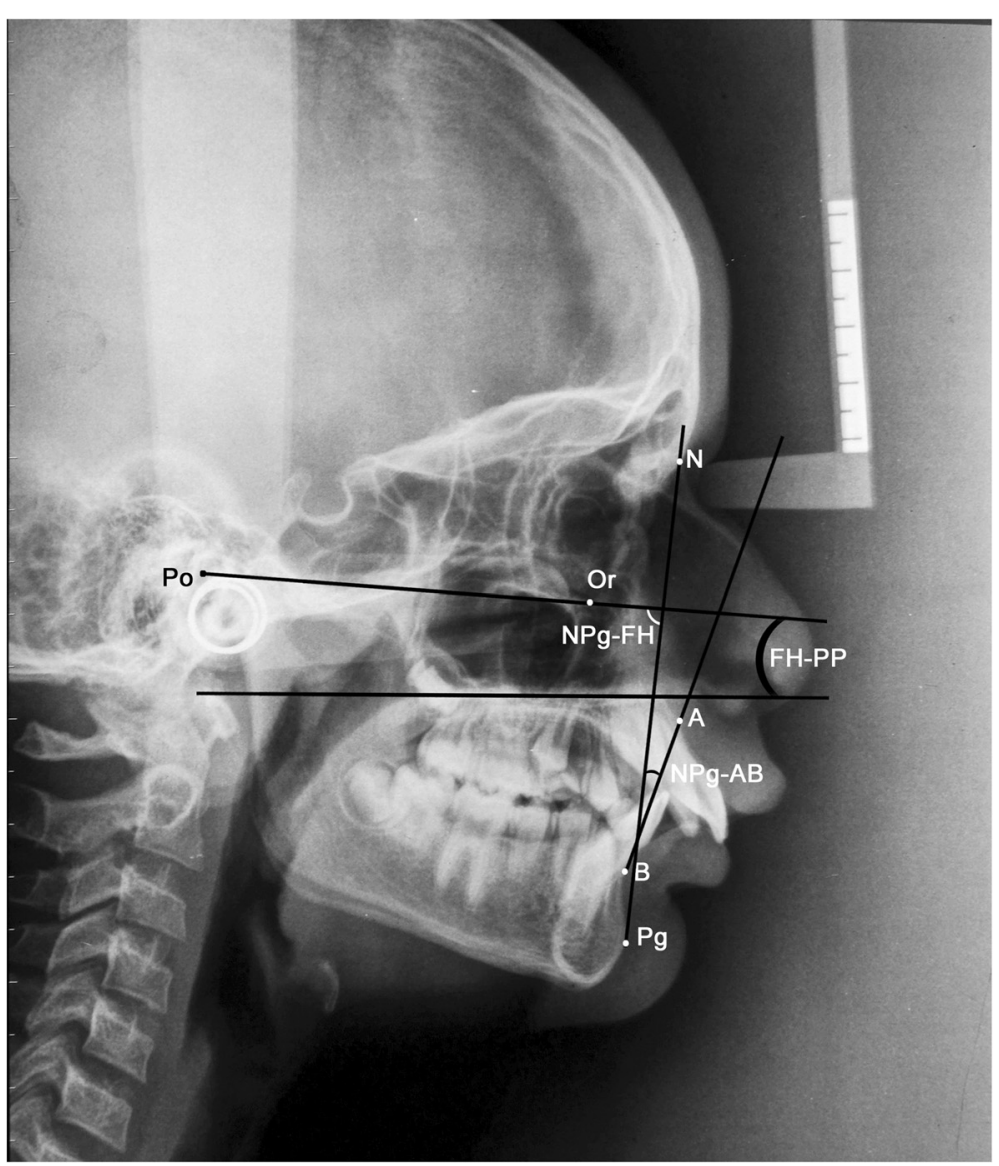

Figure 5 Angular parameter APDI.

Table 2 shows that there is a highly significant change in the pre-treatment (T1) and post-functional (T2) values of all the seven parameters considered in our study ( $p=<0.0001)$, suggesting that the sagittal change produced by the twin block is assessed accurately by all the seven parameters, thus confirming that any of the above parameters can be used reliably to assess anteroposterior discrepancy.

One of the oldest and widely used parameter is the ANB angle [6]; however, the stability of the nasion point is questionable as shown in growth studies by Nanda [20]. The rotation of the head sideways or upwards, rotation of the jaws either due to growth or orthodontic treatment, and rotation of the S-N plane also can affect the value of the ANB angle. Position of point A is affected by alveolar bone remodeling associated with orthodontic tooth movement of the upper incisor. Binder proposed that even the change in the vertical distance between points A and B without any change in the sagittal position may affect the ANB angle [21]. But the results of recent studies indicate that the ANB angle is still a reliable indicator to assess anteroposterior skeletal change before and after treatment, in spite of its limitation in diagnosis [22].
According to Table 3, 4, and 5, results showed that all the angular parameters vary independent of the ANB angle. Thus, it is suggested that when the abovementioned limitations of the ANB angle are anticipated, any of the other angular parameters such as the $\beta$ angle (mean difference $=-12.40, r=-0.527$ ), APDI (mean difference $=-11.60, r=-0.420), \mathrm{W}$ angle (mean difference $=-8.04, r=-0.613$ ), YEN angle (mean difference $=$ $-8.64, r=-0.445)$, and especially $\mathrm{W}$ angle can be used to assess anteroposterior skeletal discrepancy as the limitations of the ANB angle are less likely to influence their values. Ishikawa et al. in their study found similar values for ANB and APDI [23]. Among the angular parameters considered, the $\mathrm{W}$ angle showed the highest correlation with the ANB angle (mean difference $=-8.04, p=<0.0001$, $r=-0.613)$.

Owing to the limitations of ANB, Jacobson came up with the Wits analysis [7]. Comparison of the linear parameters (Wits analysis and App-Bpp) from Tables 4 and 5 suggests that they do not vary independent of each other (mean difference $=-0.74, p=0.949, r=0.475$ ) which indicates a non-significant correlation between Wits and App-Bpp. Therefore, in cases where Wits analysis does 


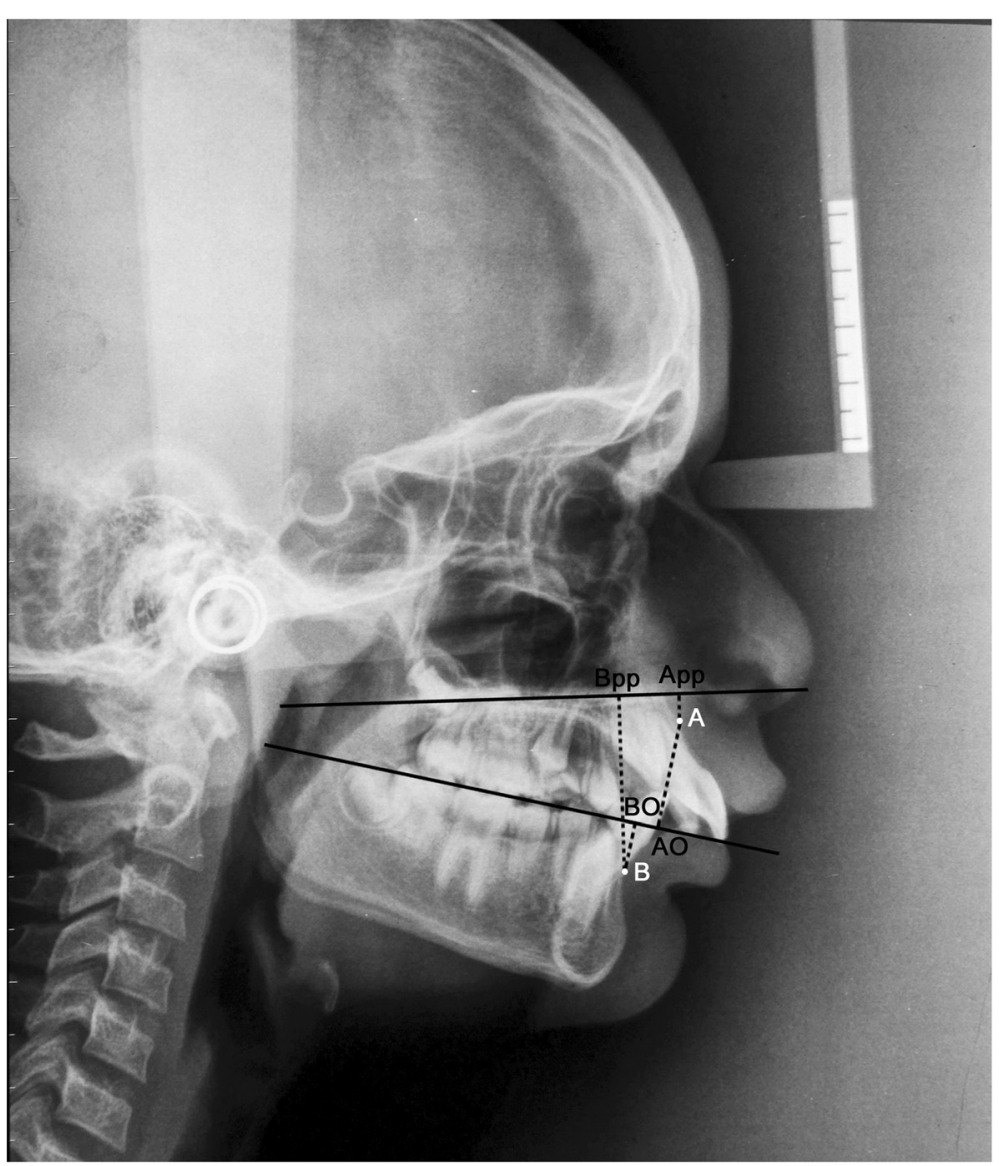

Figure 6 Linear parameters App-Bpp and Wits appraisal.

Table 2 Paired sample t-test comparing pre-treatment (T1) and post-functional (T2) values

\begin{tabular}{|c|c|c|c|c|c|c|}
\hline & Mean & $N$ & Standard deviation & Standard error of the mean & Mean difference & $p$ value \\
\hline ANB angle (T1) & 7.36 & 25 & 1.469 & 0.294 & -3.84 & $<0.0001^{*}$ \\
\hline ANB angle (T2) & 3.52 & 25 & 1.388 & 0.278 & & \\
\hline Wits appraisal (T1) & 6.72 & 25 & 2.092 & 0.418 & -5.46 & $<0.0001^{*}$ \\
\hline Wits appraisal (T2) & 1.26 & 25 & 1.849 & 0.37 & & \\
\hline$\beta$ angle (T1) & 19.12 & 25 & 3.153 & 0.631 & 8.56 & $<0.0001^{*}$ \\
\hline$\beta$ angle (T2) & 27.68 & 25 & 3.024 & 0.605 & & \\
\hline APDI (T1) & 70.2 & 25 & 3.64 & 0.728 & 7.76 & $<0.0001^{*}$ \\
\hline APDI (T2) & 77.96 & 25 & 3.702 & 0.74 & & \\
\hline App-Bpp (T1) & 12.52 & 25 & 2.801 & 0.56 & -4.72 & $<0.0001^{*}$ \\
\hline App-Bpp (T2) & 7.8 & 25 & 2.179 & 0.436 & & \\
\hline YEN angle (T1) & 114.12 & 25 & 4.799 & 0.96 & 4.8 & $<0.0001^{*}$ \\
\hline YEN angle (T2) & 118.92 & 25 & 5.227 & 1.045 & & \\
\hline$W$ angle $(T 1)$ & 49.52 & 25 & 3.38 & 0.676 & 4.2 & $<0.0001^{*}$ \\
\hline W angle (T2) & 53.72 & 25 & 3.361 & 0.672 & & \\
\hline
\end{tabular}

$\mathrm{T} 1$, pre-treatment; $\mathrm{T} 2$, post-functional; * $p \leq 0.05$ = significant. 
Table 3 Analysis of variance test between the parameters

\begin{tabular}{|c|c|c|c|c|c|}
\hline Parameter & $N$ & & Mean & Standard deviation & Standard error \\
\hline ANB angle & 25 & & -3.84 & 1.028 & 0.206 \\
\hline Wits appraisal & 25 & & -5.46 & 2.291 & 0.458 \\
\hline$\beta$ angle & 25 & & 8.56 & 3.097 & 0.619 \\
\hline APDI & 25 & & 7.76 & 3.767 & 0.753 \\
\hline App-Bpp & 25 & & -4.72 & 2.132 & 0.426 \\
\hline YEN angle & 25 & & 4.80 & 2.661 & 0.532 \\
\hline W angle & 25 & & 4.20 & 2.102 & 0.420 \\
\hline \multirow[t]{2}{*}{ Total } & 175 & & 1.61 & 6.194 & 0.468 \\
\hline & Sum of squares & $D f$ & Mean square & $F$ & Overall ANOVA $p$ value \\
\hline Difference between parameters & $5,569.134$ & 6 & 928.189 & 140.853 & $<0.0001^{*}$ \\
\hline Total & $6,676.214$ & 174 & & & \\
\hline
\end{tabular}

${ }^{*} p \leq 0.05=$ significant.

not accurately depict the maxillo-mandibular relationship, App-Bpp also may give erroneous readings. However, since Wits analysis utilizes the occlusal plane, the value can be easily affected due to orthodontic treatment and incomplete tooth eruption. Accurate identification of the occlusal plane and its reproducibility in mixed dentition, open bite, canted occlusal plane, multiple impactions, and skeletal asymmetry subjects is difficult [24]. The palatal plane is considered to be more stable than the occlusal plane [8]. Thus, in cases where identification of anatomic landmarks required for Wits analysis is not clear, it is suggested to use App-Bpp in lieu of Wits analysis. However, when the palatal plane is severely tipped, App-Bpp may also give erroneous readings [8]. In such instances, Wits analysis can be used reliably.

According to Tables 4 and 5 , it is suggested that either the YEN angle or W angle can be used to assess skeletal anteroposterior discrepancy (mean difference $=-0.6, p=0.982, r=0.894)$. With reference to the YEN angle, jaw rotations due to growth and treatment can mask true skeletal dysplasia [25]. The YEN angle requires accurate tracing of the premaxilla for its assessment. The $\mathrm{W}$ angle also requires accurate tracing of the premaxilla and locating its center, which is difficult. Also, determining which of the jaws is prognathic or retrognathic is difficult [12]. Thus, when accurate tracing of the premaxilla for the assessment of the $\mathrm{W}$ angle and YEN angle is not possible, the $\beta$ angle can be used as it shows least correlation with the YEN angle and $\mathrm{W}$ angle (Tables 4 and 5).

No significant change in the mean of the difference between T1 and T2 values of the $\beta$ angle and APDI was found (mean difference $=0.8, p=0.927, r=0.455$ ) (Tables 4 and 5). The $\beta$ angle uses the condylion as a reference point, but its identification on a closed mouth lateral cephalogram is difficult [26-28]. Thus, APDI can be used in lieu of the $\beta$ angle when locating the condylion is difficult.

Table 4 Post hoc tests (Tukey HSD): multiple comparisons

\begin{tabular}{|c|c|c|c|c|}
\hline Parameter & Parameter & Mean difference & Standard error & $p$ value \\
\hline ANB angle & $\beta$ angle & -12.40 & 0.726 & $<0.0001^{*}$ \\
\hline ANB angle & APDI & -11.60 & 0.726 & $<0.0001^{*}$ \\
\hline ANB angle & YEN angle & -8.64 & 0.726 & $<0.0001^{*}$ \\
\hline ANB angle & W angle & -8.04 & 0.726 & $<0.0001^{*}$ \\
\hline Wits appraisal & App-Bpp & -0.74 & 0.726 & 0.949 \\
\hline$\beta$ angle & APDI & 0.80 & 0.726 & 0.927 \\
\hline$\beta$ angle & YEN angle & 3.76 & 0.726 & $<0.0001^{*}$ \\
\hline$\beta$ angle & W angle & 4.36 & 0.726 & $<0.0001^{*}$ \\
\hline APDI & YEN angle & 2.96 & 0.726 & 0.001 \\
\hline APDI & W angle & 3.56 & 0.726 & $<0.0001^{*}$ \\
\hline YEN angle & W angle & 0.60 & 0.726 & 0.982 \\
\hline
\end{tabular}

${ }^{*} p \leq 0.05$ = significant. 
Table 5 A correlation matrix for the seven parameters calculated with the Karl Pearson correlation test

\begin{tabular}{|c|c|c|c|c|c|c|c|}
\hline & ANB angle & Wits appraisal & $\beta$ angle & APDI & App-Bpp & YEN angle & W angle \\
\hline \multirow[t]{3}{*}{ ANB angle } & Pearson correlation $(r)$ & 0.563 & -0.527 & -0.420 & 0.530 & -0.445 & -0.613 \\
\hline & Significance (two-tailed) $(p)$ & $0.003^{*}$ & $0.007^{*}$ & $0.037^{*}$ & $0.006^{*}$ & $0.026^{*}$ & $0.001^{*}$ \\
\hline & $n$ & & 25 & 25 & 25 & 25 & 25 \\
\hline \multirow[t]{3}{*}{ Wits appraisal } & Pearson correlation $(r)$ & & -0.552 & -0.185 & 0.475 & -0.217 & -0.383 \\
\hline & Significance (two-tailed) $(p)$ & & $0.004^{*}$ & 0.377 & $0.016^{*}$ & 0.297 & 0.059 \\
\hline & $n$ & & & 25 & 25 & 25 & 25 \\
\hline \multirow[t]{3}{*}{$\beta$ angle } & Pearson correlation $(r)$ & & & 0.455 & -0.441 & 0.328 & 0.424 \\
\hline & Significance (two-tailed) $(p)$ & & & $0.022^{*}$ & $0.027^{*}$ & 0.110 & $0.035^{*}$ \\
\hline & $n$ & & & & 25 & 25 & 25 \\
\hline \multirow[t]{3}{*}{ APDI } & Pearson correlation $(r)$ & & & & -0.552 & 0.593 & 0.591 \\
\hline & Significance (two-tailed) $(p)$ & & & & $0.004^{*}$ & $0.002^{*}$ & $0.002^{*}$ \\
\hline & $n$ & & & & & 25 & 25 \\
\hline \multirow[t]{3}{*}{ App-Bpp } & Pearson correlation $(r)$ & & & & & -0.548 & -0.655 \\
\hline & Significance (two-tailed) $(p)$ & & & & & $0.005^{*}$ & $0.0004^{*}$ \\
\hline & $n$ & & & & & & 25 \\
\hline \multirow[t]{3}{*}{ YEN angle } & Pearson correlation $(r)$ & & & & & & 0.894 \\
\hline & Significance (two-tailed) (p) & & & & & & $<0.0001^{*}$ \\
\hline & $n$ & & & & & & 25 \\
\hline \multirow[t]{3}{*}{ W angle } & Pearson correlation $(r)$ & & & & & & \\
\hline & Significance (two-tailed) $(p)$ & & & & & & \\
\hline & $n$ & & & & & & \\
\hline
\end{tabular}

The ability of the angular and linear parameters considered in our study to predict the amount of post-functional change in the maxillo-mandibular relation was analyzed with regression equations (Table 6), and it was found that the YEN angle may reliably predict post-functional change when twin block appliance is used. Strong predictability was also found for the W angle $\left(r=0.81, r^{2}=0.65\right)$ and ANB angle $\left(r=0.74, r^{2}=0.55\right)$. Although the ANB angle showed the least error (Table 6), it has to be kept in mind that the normal range in ANB for different classes of malocclusion is also relatively small. App-Bpp showed better predictability when compared to Wits analysis (Table 6).
These results are in contrast to those of Ishikawa et al. for the parameters ANB, Wits, and APDI [23].

Whenever limitations of any of the parameters used in our study are expected to cloud the clinical judgment in assessing skeletal anteroposterior relationship, use of more than one parameter in conjunction with others as described in our study is suggested.

\section{Conclusions}

Twenty-five subjects were treated with twin block appliance, and the change in their maxillo-mandibular relation was assessed with five angular and two linear parameters.

Table 6 Correlation coefficient and regression equation

\begin{tabular}{lcccc}
\hline Parameter & $\boldsymbol{r}$ & $\boldsymbol{r}^{2}$ & Equation & Standard error of the estimate \\
\hline ANB angle & 0.74 & 0.55 & $Y=0.702^{*} X-1.645$ & 0.95 \\
Wits appraisal & 0.33 & 0.11 & $Y=0.291^{*} X-0.696$ & 1.78 \\
$\beta$ angle & 0.50 & 0.25 & $Y=0.478^{*} X+18.549$ & 2.68 \\
APDI & 0.47 & 0.22 & $Y=0.482^{*} X+44.140$ & 3.33 \\
App-Bpp & 0.66 & 0.43 & $Y=0.513^{*} X+1.375$ & 1.67 \\
YEN angle & 0.86 & 0.74 & $Y=0.940^{*} X+11.697$ & 2.70 \\
W angle & 0.81 & 0.65 & $Y .801^{*} X+14.059$ & 2.03 \\
\hline
\end{tabular}

$r$, the multiple correlation coefficient; $r^{2}$, the coefficient of determination, is the squared value of the multiple correlation coefficient. 
1. All the angular and linear parameters considered in our study are reliable in assessing skeletal sagittal discrepancy.

2. Recently advocated angular parameters, especially the $\mathrm{W}$ angle, can be used reliably in place of the ANB angle whenever drawbacks of the ANB angle are anticipated.

3. As the palatal plane is more stable than the occlusal plane, it is suggested to use App-Bpp instead of Wits analysis.

4. The YEN angle and $W$ angle show the highest correlation among the parameters, which suggests that either of them can be used to assess anteroposterior jaw discrepancy.

5. Then YEN angle may reliably predict the post-functional change with the use of twin block appliance.

\section{Abbreviations}

T1: Pre-treatment; T2: Post-functional.

\section{Competing interests}

The authors declare that they have no competing interests.

\section{Authors' contributions}

RT carried out the initial drafting and framing of the study and the interpretation of data. AB carried out the analysis and interpretation of data. FM has been involved in the critical revision of the manuscript for important intellectual content and agreed to be accountable for all aspects of the work in ensuring that questions related to the accuracy or integrity of any part of the work are appropriately investigated and resolved. DP has been involved in the analysis and interpretation of data and final approval of the version to be published. HP carried out the analysis and interpretation of data. VG was involved in the data collection, drafting and framing of the study, analysis and interpretation, and preparation of the manuscript. All authors read and approved the final manuscript.

\section{Author details}

'Department of Orthodontics, Government Dental College and Hospital, Asarva, Ahmedabad, 380016, Gujarat, India. ${ }^{2}$ AMC Dental College, Ahmedabad, 380008, Gujarat, India.

Received: 23 November 2014 Accepted: 27 January 2015

Published online: 25 February 2015

\section{References}

1. Proffit WR. Prevalence of malocclusion and orthodontic treatment need in the United States: estimates from the NHANES III survey. Int J Adult Orthod Orthognath Surg.1998;13:97-106.s

2. Kelly JE, Sanchez M, Van Kirk LE. An assessment of the occlusion of the teeth of children: 6-11 years. Vital and Health Statistics, series 11, number 130. Washington, DC: US Public Health Service; 1977.

3. Kelly JE, Harvey CR. An assessment of the occlusion of the teeth of youths: 12-17 years. Vital and Health Statistics, series 11, number 162. Washington, DC: US Public Health Service; 1977.

4. Kharbanda OP. Orthodontics: diagnosis and management of malocclusion and dentofacial deformities. New Delhi: Elsevier; 2013. p. 459.

5. McNamara JA. Components of class II malocclusion in children 8-10 years of age. Angle Orthod. 1981;51:177-202.

6. Riedel RA. The relation of maxillary structures to cranium in malocclusion and in normal occlusion. Angle Orthod. 1952;22:142-5.

7. Jacobson A. The "Wits" analysis of jaw disharmony. Am J Orthod. 1975;67(2):125-38.

8. Nanda RS, Merrill RM. Cephalometric assessment of sagittal relationship. Am J Orthod. 1994;105(4):328-44.

9. Baik CY, Ververidou M. A new approach of assessing sagittal discrepancies: the Beta angle. Am J Orthod. 2004;126:100-5.
10. Kim YH, Vietas JJ. Anteroposterior dysplasia indicator: an adjunct to cephalometric differential diagnosis. Am J Orthod. 1978;73:619-33.

11. Neela PK, Mascarenhas R, Husain A. A new sagittal dysplasia indicator: the YEN angle. World J Orthod. 2009;10:147-51.

12. Bhad WA, Nayak S, Doshi UH. A new approach of assessing sagittal dysplasia: the W angle. Eur J Orthod 2013(1):66-70.

13. Oktay H. Comparison of ANB, WITS, AF-BF, and APDI measurements. Am J Orthod Dentofacial Orthop. 1991;99:122-8.

14. Han UK, Kim YH. Determination of class II and class III skeletal patterns: receiver operating characteristic (ROC) analysis on various cephalometric measurements. Am J Orthod Dentofacial Orthop. 1998;113:538-45.

15. Moyers RE, Bookstein FL, Guire KE. The concept of pattern in craniofacial growth. Am J Orthod. 1979;76:136-48.

16. Nanda R. Biomechanics and esthetic strategies in clinical orthodontics. St. Louis: Elsevier; 2005. p. 38-73.

17. Mills CM, Mcculloch KJ. Treatment effects of the twin block appliance: a cephalometric study. Am J Orthod. 1998;114(1):15-24.

18. Mills CM, Mcculloch KJ. Posttreatment changes after successful correction of class II malocclusions with the twin block appliance. Am J Orthod. 2000;118(1):24-33.

19. Jena AK, Duggal R. Treatment effects of twin-block and mandibular protraction appliance-IV in the correction of class II malocclusion. Angle Orthod. 2010;80(3):485-91.

20. Hussels W, Nanda RS. Analysis of factors affecting angle ANB. Am J Orthod. 1984;85(5):411-23.

21. Binder RE. The geometry of cephalometrics. J Clin Orthod 1979;13;256-263.

22. Xu TM, Ahn J, Boyd RM, Baumrind S. Sensitivity of angular cephalometric measures. J Dent Res, 1997, 76 (special issue):160

23. Ishikawa H, Nakamura S, Iwasaki H, Kitazawa S. Seven parameters describing anteroposterior jaw relationships: postpubertal prediction accuracy and interchangeability. Am J Orthod Dentofacial Orthop 2000;117(6):714-20

24. Del Santo Jr M. Influence of occlusal plane inclination on ANB and Wits assessments of anteroposterior jaw relationships. Am J Orthod. 2006;129:641-8.

25. Ghafari J, Baumrind S, Efstratiadis SS. Misinterpreting growth and treatment outcome from serial cephalographs. Clin Orthod Res. 1998;1:102-6.

26. Adenwalla ST, Kronman JH, Attarzadeh F. Porion and condyle as cephalometric landmarks: an error study. Am J Orthod. 1988;94(5):411-5.

27. Moore RN, DuBois LM, Boice PA, Igel KA. The accuracy of measuring condylion location. Am J Orthod. 1989;95(4):344-7.

28. Al-Mashhadany SM. The relation between W angle and other methods used to assess the sagittal jaw relationship. J Bagh Coll Dentistry. 2012;24(2):144-9

\section{Submit your manuscript to a SpringerOpen ${ }^{\circ}$ journal and benefit from:}

- Convenient online submission

- Rigorous peer review

- Immediate publication on acceptance

- Open access: articles freely available online

- High visibility within the field

- Retaining the copyright to your article

Submit your next manuscript at $\gg$ springeropen.com 